\title{
Evaluation and Utilization of Nano-Micron Polymer Plug for Heterogeneous Carbonate Reservoir with Thief Zones
}

\author{
Chenji Wei ${ }^{D},{ }^{1}$ Jie Zheng, ${ }^{1}$ Lihui Xiong, ${ }^{1}$ Zhengzhong Li, ${ }^{1}$ Jian Yang, ${ }^{1}$ Jingjian Zhang, \\ Shiyao Lin, ${ }^{3}$ Linlang Zhou, ${ }^{4}$ Lichun Fang, ${ }^{1}$ and Yutao Ding ${ }^{3}$ \\ ${ }^{1}$ Research Institute of Petroleum Exploration and Development, PetroChina, Beijing, China \\ ${ }^{2}$ China Petroleum Technology and Development Corporation, PetroChina, Beijing, China \\ ${ }^{3}$ China National Oil and Gas Exploration and Development Company Ltd., Beijing, China \\ ${ }^{4}$ China Petroleum Southwest Oil and Gas Field Company Chuanzhong Oil and Gas Mine, Beijing, China
}

Correspondence should be addressed to Chenji Wei; weicj1212@126.com

Received 4 June 2019; Accepted 29 November 2019; Published 12 January 2020

Guest Editor: Jianchao Cai

Copyright ( 2020 Chenji Wei et al. This is an open access article distributed under the Creative Commons Attribution License, which permits unrestricted use, distribution, and reproduction in any medium, provided the original work is properly cited.

Thief zones are highly permeable zones in oil reservoirs which affect the performance greatly during water flooding. The most effective way to prevent the invalid circle of thief layer is the injection of high-concentration polymer slugs. In this paper, the plugging effect of nano-micron polymer flooding on the thief zone is studied by experimental and theoretical analysis. The changes of water content and flow resistance were analyzed under different conditions. The result shows that the model presented here has good agreement with the experimental results. The displacement effect is the best when the thief zone is located on the upper part of the reservoir. And the water content will decrease with the increase of flow resistance after nano-micron polymer injection. Besides, the higher the polymer concentration, the more obvious the decrease of water content, and more effective the plugging. This study has provided a quick and reasonable guide in the later adjustment of water flooding development of carbonate reservoirs with thief layers.

\section{Introduction}

Carbonate reservoir refers to the accumulation of oil and gas in carbonate traps. And it is one of the most important hydrocarbon reservoirs in the world, which accounts for about half of the global reserves. The proportion of the output has reached more than $60 \%$ of the total output. Compared with the conventional sandstone reservoir, the development efficiency of the carbonate reservoir is lower. Carbonate reservoirs have typical characteristics of multiple media and serious permeability heterogeneity [1-4].

Because of the strong heterogeneity and complicated reservoir structure, invalid cycle channels easily appear in carbonate reservoirs. The permeability of the invalid cycle channels is very high, and most of the water flows through this area during water flooding, which greatly reduces the effective utilization area and displacement efficiency. And then, the formation pressure of the carbonate reservoir declines rapidly under the exploitation method with natural energy, which will lead to low efficiency [5-8]. Most oil fields use water injection to supplement the pressure loss. But long-time water injection can also cause damage to the reservoir and water circulate inefficiently, which is unfavorable to enhance the overall recovery of the oil field.

The result of PLT logging in many oil fields shows that there is a thin layer with high permeability, and most of the production fluid comes from this layer. The contribution ratio of the layer is far beyond its thickness ratio, and we call them "thief zones", which is one of the important manifestations of heterogeneity in carbonate reservoirs [9-11]. In the process of water injection, large amounts of water tend to flow through the thief zone, which results in water breakthrough quickly and low recovery. Therefore, how to identify and characterize these thief zones effectively has been increasingly attracting reservoir engineers' attention [12-15]. 
There are several techniques to research and characterize the thief zones. Generally speaking, there are core analysis, well logging, well testing, and reservoir engineering methods. Although these methods can calculate and characterize the specific parameters of thief zones, it is always time consuming and expensive compared with the theoretical method and numerical simulation, and they cannot determine the level of the thief zone [16-21].

To meet the needs of water injection in different stages of oil field development, the technology of stratified water flood has been started since the 80 s of the last century, which could enhance oil recovery greatly [22]. For vertically heterogeneous reservoirs, the method of stratified water flood can avoid the formation of dominant channels, slow down the rate of water cut increase, and ultimately improve the recovery rate of oil reservoirs. In addition, for heterogeneous reservoirs, using water polymer alternative flooding can achieve the purpose of blocking large channels, improving the sweep area, and ultimate recovery $[23,24]$. The nanomicron polymer dispersion system has the characteristics of water swelling, which makes it expand rapidly in the process of injection into the high water-cut layer, slows down the flow rate of fluid, and then plays a role in plugging $[25,26]$.

In this paper, firstly, a mathematical model considering the flow resistance is established to study the effect of polymer plug on the thief zone. Secondly, the plugging effect of polymer flooding on the thief zone is studied by experimental analysis. The result shows that the present model has good agreement with the experimental results. The water displacement effect is the best when the thief zone is located on the upper part of the reservoir. And the water content will decrease with the increase of flow resistance after the polymer injection. In addition, the higher the polymer concentration, the more obvious the decrease of water content, and the more effective of the plugging. This study has provided a quick and reasonable guide in the later adjustment of water flooding development of carbonate reservoirs with thief layers.

\section{Mathematical Model}

2.1. Flow Resistance Model of the Nano-Micron Polymer Expansion System. Flow resistance is the most important factor to affect the fluid flow, especially in the reservoirs with strong heterogeneity, which have a great influence on the water distribution of different layers. In addition, gravity also plays an important role in fluid flow in heterogeneous reservoirs. To avoid the formation of an invalid cycle channel, we inject the polymer with high concentration to increase the flow resistance and then increase the swept area. Because of gravity, the fluid has a flow potential in the direction of gravity, so when the horizontal direction is plugged, the flow potential of the area below is stronger, which results in a larger swept area. The location of the polymer plug also has a great influence on the swept area as shown in Figure 1.

In this paper, we studied the mathematical mechanism of polymer flooding to improve the displacement efficiency of reservoirs with the thief zone using the method of flow resistance.
The basic assumptions used in this study are as follows: (1) constant rate production; (2) closed boundary condition; (3) capillary pressure influences are negligible; (4) the reservoir temperature is constant; and (5) the permeability is isotropic.

The motion equation fully describing the multiphase flow characteristics is:

$$
\vec{v}_{j}=-\frac{K K_{r j}}{\mu_{j}}\left(\nabla p+\rho_{j} g\right),
$$

where $j=o, w, p, \vec{v}_{j}$ is the velocity of fluids, $K$ is absolute permeability of the reservoir, $K_{r j}$ is the relative permeability of oil-water-polymer (three-phase), $\mu_{j}$ is the viscosity of fluids, $\nabla p$ is the differential pressure, $\rho_{j}$ is the density of fluids, and $g$ is the acceleration of gravity.

According to the similarity theory of hydropower, we can obtain the water injection rate and the productivity of each layer [27].

$$
Q_{i}=\frac{P}{R_{i}}
$$

Water injection layer:

$$
R_{i}=\frac{1}{2 \pi h_{i} k_{i} f_{i, 1}} \ln \frac{r_{i, 1}}{r_{w}}+\frac{1}{2 \pi h_{i} k_{i} f_{i, 1}} \ln \frac{r_{e}}{r_{i, 1}} .
$$

Thief zone:

$$
\begin{aligned}
R_{t h}= & \frac{1}{2 \pi h_{t h} k_{t h} f_{t h, 1}} \ln \frac{r_{t h, 1}}{r_{w}}+\frac{1}{2 \pi h_{t h} k_{t h} f_{t h, 2}} \ln \frac{r_{t h, 2}}{r_{t h, 1}} \\
& +\frac{1}{2 \pi h_{i} k_{i} f_{t h, 3}} \ln \frac{r_{e}}{r_{t h, 2}} .
\end{aligned}
$$

The total flow resistance:

$$
R_{t}=\frac{1}{\left(1 / R_{t h}\right)+\sum_{i=1} 1 / R_{1}}
$$

where $f_{i, n}=\left(k_{r o i, n} / \mu_{o}\right)+\left(k_{r w i, n} / \mu_{w, n}\right)$ is the slug fluidity, $i$ is the number of the layer, $R_{i}$ is resistance of layer $i, h_{i}$ is the thickness of layer $i, k_{i}$ is permeability of layer $i, P_{j}$ is the pressure of oil-water (two phases) considering gravity, $r_{e}$ is the well spacing, $r_{w}$ is the radius of the wellbore. $Q_{i}$ is liquid production of each layer, $\bar{P}$ is the average formation pressure, and $Q_{t}$ is the total water injection rate.

And equation (1) shows that the flow velocity is a vector, and there is also a flow velocity in the vertical direction influenced by gravity. So we must consider the gravity when we calculate the flow resistance. And then the new flow resistance equation is obtained as follows:

Upward flow:

$$
Q_{v i}=\frac{P-\rho_{w} g}{R_{v i}}=\frac{P-\rho_{w} g}{\alpha R_{i}} .
$$

Downward flow:

$$
Q_{v i}=\frac{P+\rho_{w} g}{R_{v i}}=\frac{P+\rho_{w} g}{\alpha R_{i}} .
$$

So if there are $n$ layers, the actual injection of each layer is 


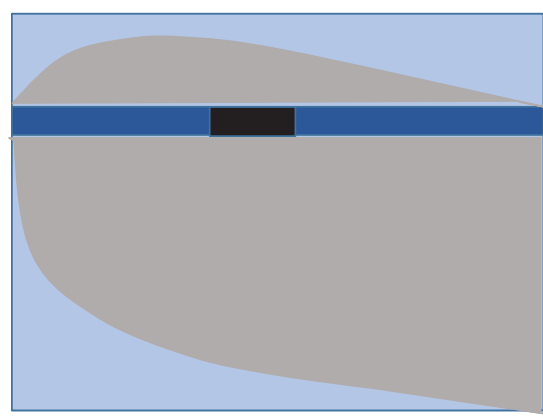

Thief zone

Polymer plug

Swept range

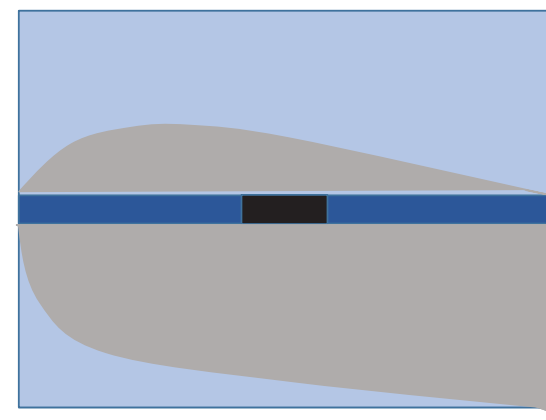

Thief zone

Polymer plug

Swept range

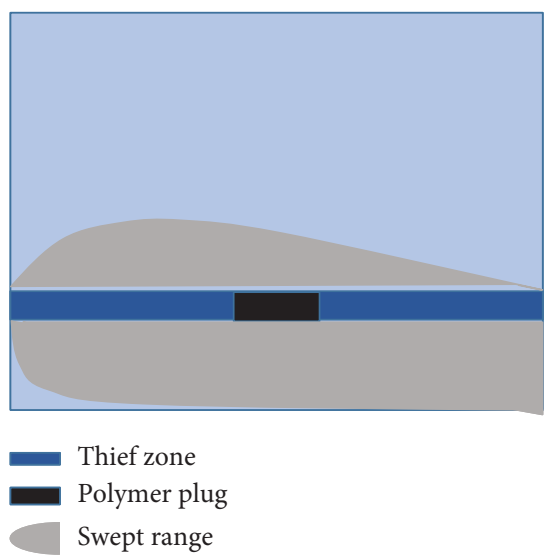

(c)

Figure 1: Diagram of the swept range of polymer flooding under different locations of the thief layer. (a) Upper. (b) Middle. (c) Bottom.

$$
\left\{\begin{array}{l}
Q_{t, i}=Q_{h, i}+Q_{v, i}=\frac{P}{R_{h, i}}+\frac{P-\rho_{w} \mathcal{g}}{\alpha R_{h, i+1}}, i=1, \\
Q_{t, i}=Q_{h, i}+Q_{v, i}=\frac{P}{R_{h, i}}+\frac{P \pm \rho_{w} \mathcal{g}}{\alpha R_{h, i \mp 1}}, n>i \geq 2, \\
Q_{t, i}=Q_{h, i}+Q_{v, i}=\frac{P}{R_{h, i}}+\frac{P+\rho_{w} g}{\alpha R_{h, i-1}}, i=n .
\end{array}\right.
$$

If there are $n$ layers, the total liquid production is $Q=$ $\sum_{i=1}^{n} Q_{t, i}$, the single-layer water production is $Q_{w, i}=$ $\bar{P} /\left(\mu_{w} / 2 \pi k_{w, i} h_{i}\right) \ln \left(r_{e} / r_{w}\right)$, and the total water production is $Q_{w}=\sum_{i=1}^{n} Q_{w, i}$.

Then the water content can be expressed as follows:

$$
f_{w}=\frac{Q_{w}}{Q}=\frac{\sum_{i=1}^{n} Q_{w, i}}{\sum_{i=1}^{n} Q_{t, i}}
$$

\section{Experiments and Model Validation}

3.1. Experimental Procedure. In this paper, we experimented with the thief zone in the middle of the model. Based on the plane unidirectional flow theoretical model, the applicability of the model is verified by experiments. The model consists of two parts: the matrix layer and thief zone, as shown in Figure 2. Matrix layer size is $4.5 \mathrm{~cm} * 4.5 \mathrm{~cm} * 60 \mathrm{~cm}$, the thickness of the thief zone is $0.3 \mathrm{~cm}$, and the specific parameters are shown in Table 1 . The experimental equipment is shown in Figure 3.

The experimental oil is a mixture of crude oil and kerosene. The whole process is carried out at $80^{\circ} \mathrm{C}$, the viscosity is $1.7 \mathrm{MPa} \cdot \mathrm{s}$, and the water salinity is 260 thousand. The specific process is as follows:

(1) Firstly, the cores need to be evacuated for 6 hours and saturated with original formation water. Then permeability was tested using formation water at the reservoir temperature $\left(80^{\circ} \mathrm{C}\right)$.

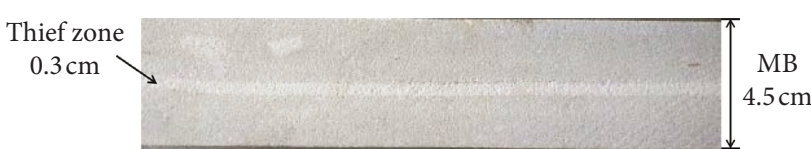

Figure 2: The experimental model of the thief zone.

TABLE 1: Core parameters of the water flooding test with the thief zone in the middle of $\mathrm{MB}$.

\begin{tabular}{lcccc}
\hline Core & Size $(\mathrm{cm})$ & $\begin{array}{c}\text { Permeability } \\
(\mathrm{mD})\end{array}$ & $\begin{array}{c}\text { Thickness } \\
(\mathrm{cm})\end{array}$ & $\begin{array}{c}\text { Porosity } \\
(\%)\end{array}$ \\
\hline $\begin{array}{l}\text { Matrix } \\
\text { layer }\end{array}$ & 50 & 2.1 & \\
$\begin{array}{l}\text { Thief } \\
\text { zone } \\
\text { Matrix } \\
\text { layer }\end{array}$ & $4.5 \times 4.5 \times 60$ & 1000 & 0.3 & 20.58 \\
\hline
\end{tabular}

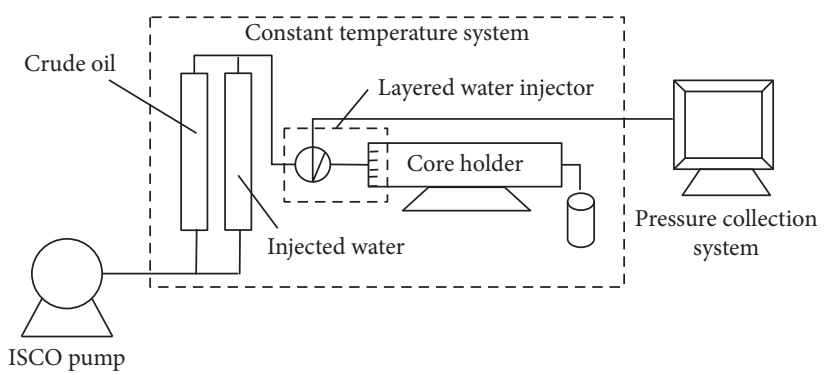

Figure 3: Experimental apparatus.

(2) Using the special heterogeneous saturated oil holder, saturated formation water in the core is displaced by crude oil to build irreducible water. The displacement speed is gradually increased until no water appears, maintaining for $24 \mathrm{~h}$.

(3) At a temperature of $80^{\circ} \mathrm{C}$, water flooding experiment is carried out through layered water injector at $1 \mathrm{~m} / \mathrm{d}$, and the experiment will end when the water content reaches $95 \%$. 


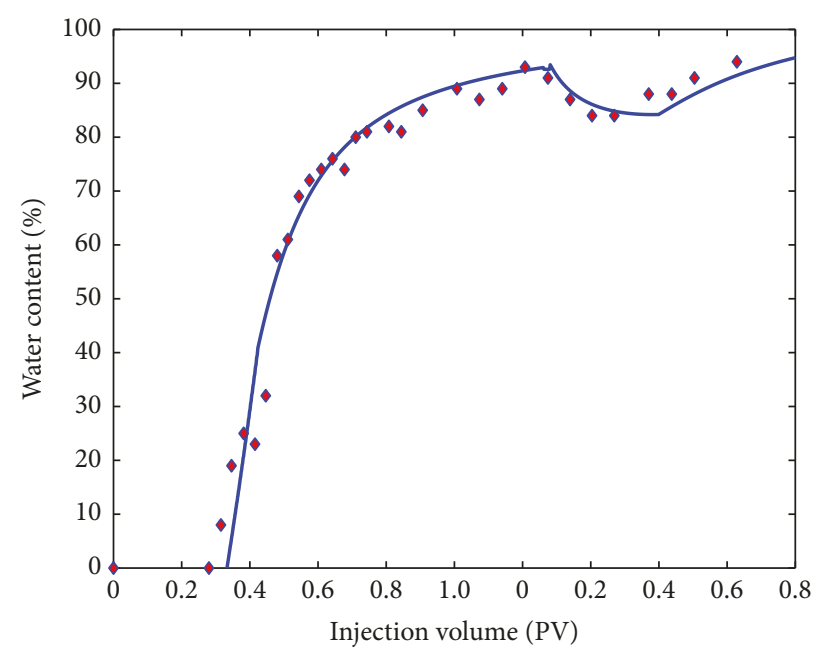

FIgURE 4: Comparison of experimental data and the presented model.

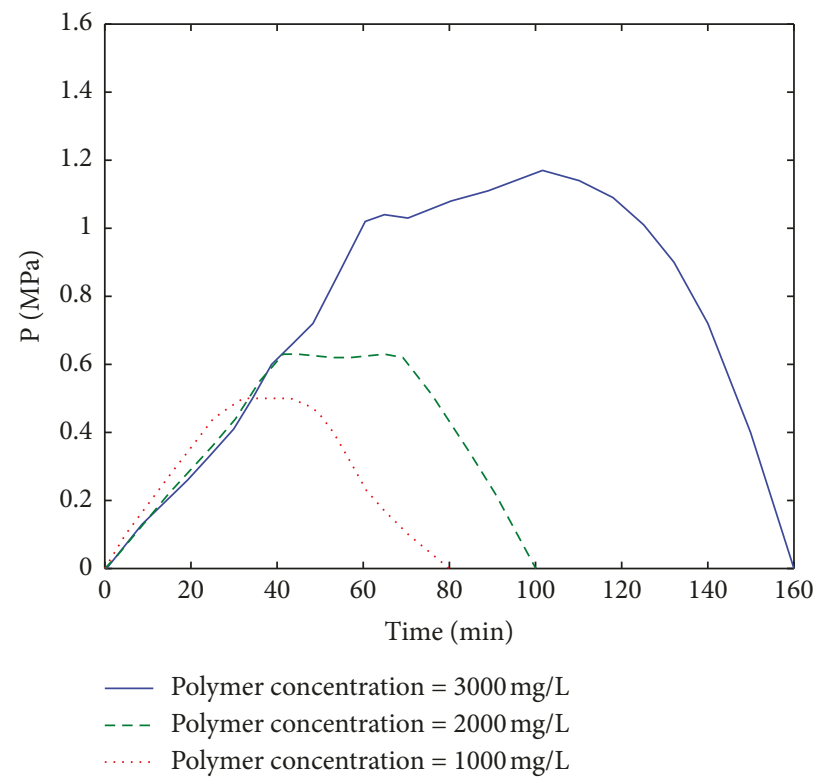

FIGURE 5: The relationship between pressure and time under different polymer concentrations.

(4) Repeating the step 3, the polymer is injected into the model when the water content reaches $90 \%$ and ended when the water content reaches $95 \%$.

(5) During the displacement process, the liquid produced from the holder is measured every $10 \mathrm{~min}$, and the oil and water output was recorded. The data are appropriately encrypted in phase with the water content of the produced liquid exceeding $90 \%$. The pressure data are automatically collected by using a computer.

3.2. Experimental Results and Model Verification. As seen in Figure 4, water began to be produced when the injection amount reached $0.17 \mathrm{PV}$, and then the water content increased rapidly. After injecting the polymer, the water content decreased gradually, and it began to grow slowly after reaching $84 \%$.

Figure 4 displays the comparison of experimental data and the presented model. The result shows that the present model has good agreement with the experimental results. Figure 5 shows the relationship between pressure and time under different polymer concentrations. The result shows that the higher the polymer concentration, the longer the pressure maintenance.

\section{Results and Discussion}

Under the reservoir size, the effect of different factors on water content is analyzed using the present model. And the thief zone is in the middle of the reservoir. The necessary physical parameters are shown in Table 2 and 3. 
TABLE 2: The reservoir physical parameters.

\begin{tabular}{lcccccc}
\hline Stratum & Oil viscosity (MPa.s) & Water viscosity (MPa.s) & Well spacing $(\mathrm{m})$ & Permeability (mD) & Thickness (m) & Porosity (\%) \\
\hline $\begin{array}{l}\text { Thief zone } \\
\text { Matrix layer }\end{array}$ & 5 & 1 & 200 & 1000 & 2 & 20.58 \\
\hline
\end{tabular}

TABLE 3: The relative permeability of the reservoir.

\begin{tabular}{lcr}
\hline Sw & Krw & Kro \\
\hline 0.35 & 0 & 1 \\
0.4107 & 0.041 & 0.725 \\
0.438 & 0.063 & 0.605 \\
0.462 & 0.082 & 0.514 \\
0.486 & 0.101 & 0.434 \\
0.51 & 0.124 & 0.362 \\
0.534 & 0.15 & 0.297 \\
0.56 & 0.178 & 0.222 \\
0.582 & 0.2 & 0.175 \\
0.606 & 0.227 & 0.121 \\
0.63 & 0.257 & 0.082 \\
0.654 & 0.285 & 0.047 \\
0.6679 & 0.305 & 0.029 \\
0.682 & 0.33 & 0.011 \\
0.69 & 0.346 & 0 \\
\hline
\end{tabular}

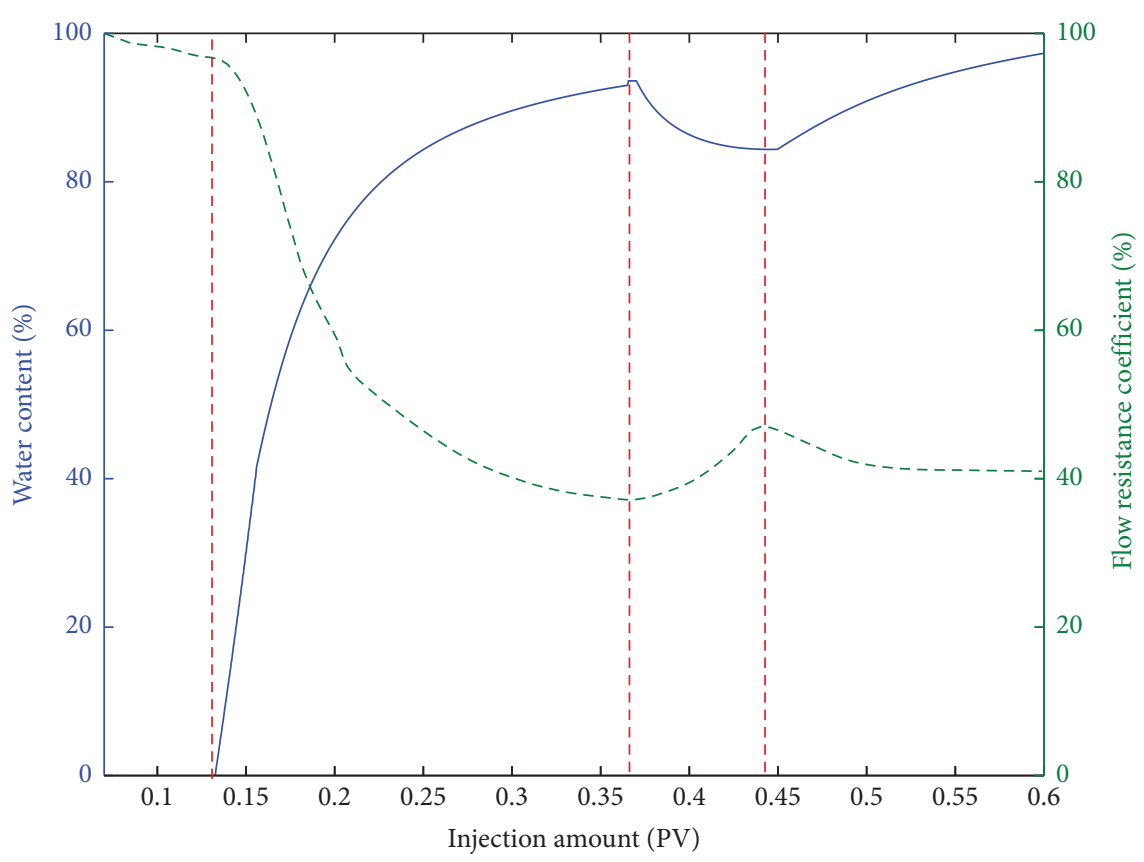

Figure 6: Curves of water content and flow resistance with time during polymer flooding.

4.1. Variation of Water Content and Flow Resistance. Figure 6 shows the variation of water content and flow resistance with time during polymer flooding. The results show that the flow resistance decreases a little bit before water breakthrough. But once it happens, the water content will increase rapidly and the flow resistance will show the opposite trend. After polymer injection, the flow resistance will be obviously raised and the water content will decrease at the same time, which is the main period of enhanced oil recovery.
4.2. Influence of Polymer Concentration on Reservoir Water Content. Figure 7 shows the relationship between the water content and injection volume under different polymer concentrations. From Figure 7, we can know that the water content decreases obviously with the increase of the polymer concentration, which has a better plugging effect. Taking into account the input-output ratio of the production, the optimal polymer concentration should be controlled within $2.5 \mathrm{~g} / \mathrm{L}$. 


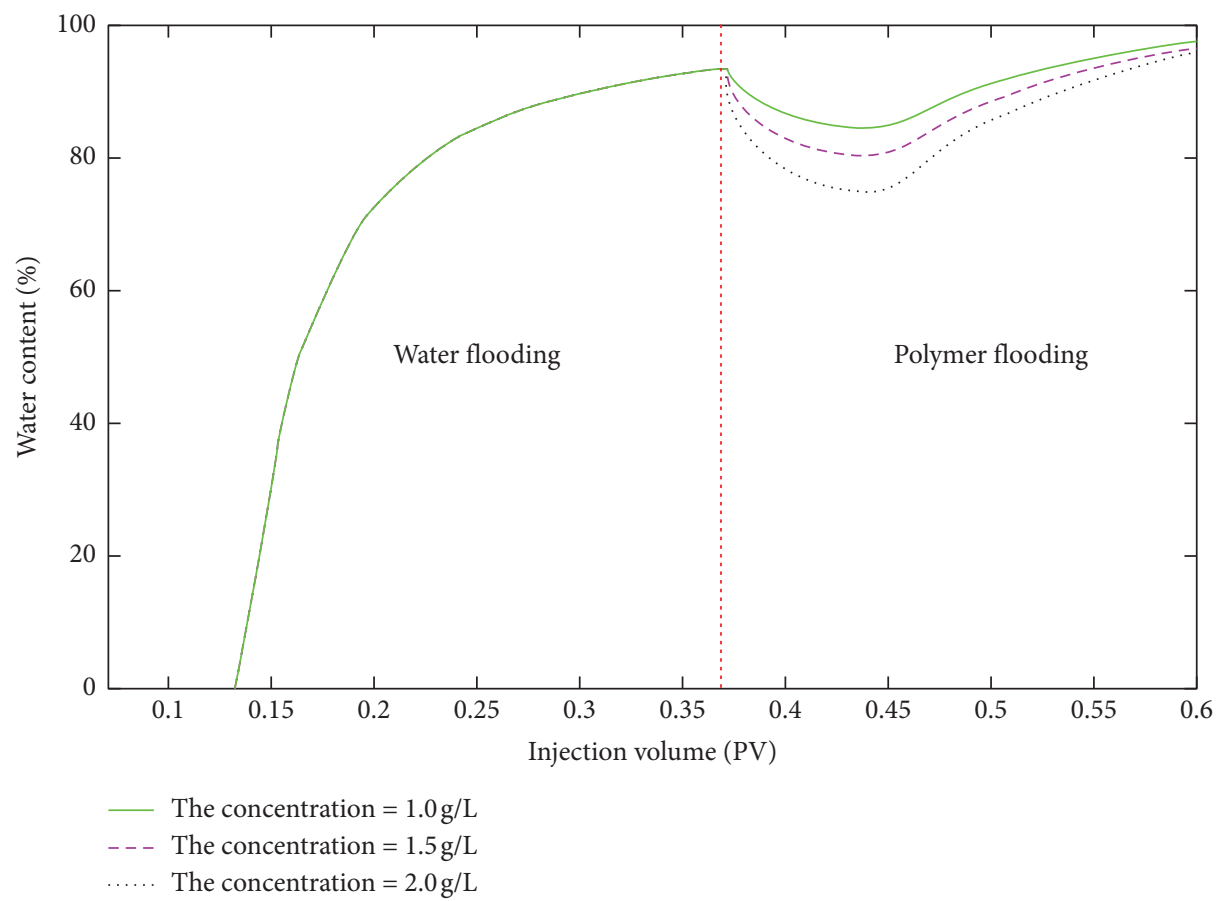

Figure 7: Water content with different polymer concentrations.

\section{Conclusion}

In this paper, the plugging effect of polymer flooding on the thief zone is studied by experimental and theoretical analysis. The changes of water content and flow resistance were analyzed under different conditions. The result shows that the present model has good agreement with the experimental results. The water displacement effect is the best when the thief zone is located on the upper part of the reservoir. And the water content will decrease with the increase of flow resistance after polymer injection. In addition, the higher the polymer concentration, the more obvious the decrease of water content, and the more effective the plugging. The optimal polymer concentration should be controlled within $2.5 \mathrm{~g} / \mathrm{L}$. This study has provided a quick and reasonable guide in the later adjustment of water flooding development of carbonate reservoirs with thief layers.

\section{Data Availability}

The data used to support the findings of this study are included within the article.

\section{Conflicts of Interest}

The authors declare that they have no conflicts of interest.

\section{Acknowledgments}

We gratefully acknowledge the National Science and Technology Major Project (Grant no. 2017ZX05030-001), the CNODC Technology Support Project (Grant no. 2018-
ZC-01-11), and the Beijing Nova Program (Grant no. Z171100001117081) for financial support.

\section{References}

[1] F. Lucia, Carbonate Reservoir Characterization, Springer, Berlin, Germany, 2007.

[2] Q. Dou, Y. Sun, and C. Sullivan, "Rock-physics-based carbonate pore type characterization and reservoir permeability heterogeneity evaluation, upper san andres reservoir, permian basin, west Texas," Journal of Applied Geophysics, vol. 74, no. 1, pp. 8-18, 2011.

[3] H. Song, Y. Cao, M. Yu, Y. Wang, J. E. Killough, and J. Leung, "Impact of permeability heterogeneity on production characteristics in water-bearing tight gas reservoirs with threshold pressure gradient," Journal of Natural Gas Science and Engineering, vol. 22, pp. 172-181, 2015.

[4] P. Sun, H. Xu, Q. Dou et al., "Investigation of pore-type heterogeneity and its inherent genetic mechanisms in deeply buried carbonate reservoirs based on some analytical methods of rock physics," Journal of Natural Gas Science and Engineering, vol. 27, pp. 385-398, 2015.

[5] R. K. Bane, R. A. Parker, W. G. Storbeck, and R. L. Sunde, "Reservoir management of the fullerton clearfork unit," in Proceedings of the Permlan Basin Oil and Gas Recovery Conference, vol. 27640, pp. 16-18, SPE, Midland, TX, USA, March 1994.

[6] Q. Hou, K. Chen, Z. Fan, L. Fu, and Y. Chen, "Major influencing factors of water flooding in abnormally highpressure carbonate reservoir," IOP Conference Series: Earth and Environmental Science, vol. 52, no. 1, Article ID 012064, 2017.

[7] X. Guo, H. Song, K. Wu, and J. Killough, "Pressure characteristics and performance of multi-stage fractured horizontal well in shale gas reservoirs with coupled flow and 
geomechanics," Journal of Petroleum Science and Engineering, vol. 163, pp. 1-15, 2018.

[8] J. Wang, H. Song, V. Rasouli, and J. Killough, "An integrated approach for gas-water relative permeability determination in nanoscale porous media," Journal of Petroleum Science and Engineering, vol. 173, pp. 237-245, 2019.

[9] M. Abdullah and A. Hisham, "Characteristics of high-permeability zones using core analysis, and production logging data," Journal of Petroleum Science and Engineering, vol. 55, no. 1, pp. 18-36, 2007.

[10] Q. Feng, S. Wang, W. Zhang, Y. Song, and S. Song, "Characterization of high-permeability streak in mature waterflooding reservoirs using pressure transient analysis," Journal of Petroleum Science and Engineering, vol. 110, pp. 55-65, 2013.

[11] T. B. N. Nguyen, T. Q. C. Dang, W. Bae, and Z. Chen, "Effects of reservoir heterogeneities, thief zone, and fracture systems on the fast-sagd process," Energy Sources, Part A: Recovery, Utilization, and Environmental Effects, vol. 36, no. 15, pp. 1710-1725, 2014.

[12] G. Mayatoro, Z. Pachóncontreras, and J. Zapataarango, "Polymer gels for controlling water thief zones in injection wells," CT\&F-Ciencia Tecnologia Y Futuro, vol. 5, no. 1, pp. 37-44, 2012.

[13] S. J. P. Oskouei, B. B. Maini, R. G. Moore, and S. A. Mehta, "Effect of initial water saturation on the thermal efficiency of the steam-assisted gravity-drainage process," Journal of $\mathrm{Ca}$ nadian Petroleum Technology, vol. 51, no. 5, pp. 351-361, 2012.

[14] N. Gershenzon, M Soltanian Jr, R. W. Ritzi, and D. F. Dominic, "Understanding the impact of open-framework conglomerates on water-oil displacements: victor interval of the ivishak reservoir, prudhoe bay field, Alaska," Petroleum Geoscience, vol. 21, no. 1, pp. 43-54, 2015.

[15] H. Han, T. Li, H. Song, Y. Wang, and J. Killough, "Experimental research on remaining oil distribution and recovery performance after immiscible and miscible CO," International Journal of Oil, Gas and Coal Technology, vol. 15, no. 1, pp. 47-59, 2017.

[16] Q. Feng, S. Wang, G. Gao, and C. Li, "A new approach to thief zone identification based on interference test," Journal of Petroleum Science and Engineering, vol. 75, no. 1-2, pp. 13-18, 2010.

[17] S. G. Ghedan, Y. A. Boloushi, and M. B. F. Saleh, "Thief zones and effectiveness of water-shut-off treatments under variable levels of gravity and reservoir heterogeneity in carbonate reservoirs," in SPE EUROPEC/EAGE Annual Conference and Exhibition, Society of Petroleum Engineers, Barcelona, Spain, June 2010.

[18] B. Li, H. Najeh, J. Lantz, M. Rampurawala, I. M. Gok, and A. K. Mohammed, "Detecting thief zones in carbonate reservoirs by integrating borehole images with dynamic measurements: case study from the mauddud reservoir, north Kuwait," SPE Reservoir Evaluation \& Engineering, vol. 13, no. 2, pp. 193-202, 2010.

[19] D. R. Harp, R. Pawar, and C. W. Gable, "Numerical modeling of cemented wellbore leakage from storage reservoirs with secondary capture due to thief zones," Energy Procedia, vol. 63, pp. 3532-3543, 2014.

[20] Q. Zhang, Y. Li, B. Li, Z. Liu, C. Wei, and J. Zhou, "Identification methods and development strategy study of thief zone in reef-bank carbonate reservoirs: a case study of the mishrif reservoir in rumaila oilfield," Petroleum Geology and Recovery Efficiency, vol. 23, no. 2, pp. 29-34, 2016.
[21] S. Wang, Q. Feng, and X. Han, "A hybrid analytical/numerical model for the characterization of preferential flow path with non-Darcy flow," PloS One, vol. 8, no. 12, Article ID e83536, 2013.

[22] W. Emad and B. Ghosh, "Effect of pore-scale heterogeneity and capillary-viscous fingering on commingled waterflood oil recovery in stratified porous media," Journal of Petroleum Engineering, vol. 2016, Article ID 1708929, 14 pages, 2016.

[23] D. O. Shah and R. S. Schechter, Eds., Improved Oil Recovery by Surfactant and Polymer Flooding, Elsevier, Amsterdam, Netherlands, 2012.

[24] B. Shaker Shiran and A. Skauge, "Enhanced oil recovery (EOR) by combined low salinity water/polymer flooding," Energy \& Fuels, vol. 27, no. 3, pp. 1223-1235, 2013.

[25] Y. Long, Y. Wang, and W. Zhu, "Numerical simulation of oil recovery enhancement by nano/micron-sized polymer particles fluid in low permeability reservoir," Electronic Journal of Geotechnical Engineering, vol. 21, no. 5, pp. 1859-1872, 2016.

[26] Y. Long, X. Huang, Y. Gao, L. Chen, F. Song, and H. Zhang, "Swelling mechanism of core-shell polymeric nanoparticles and their application in enhanced oil recovery for low permeability reservoirs," Energy \& Fuels, vol. 33, no. 4, pp. 3077-3088, 2019.

[27] H. Song, Z. Yao, W. Ming, S. Kai, and H. Tu, "Complicated controllable displacement of equivalent filtrational resistance with several slugs," Journal of University of Science and Technology Beijing, vol. 175, no. 4, pp. 926-932, 2009. 


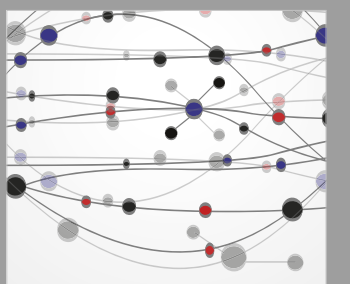

The Scientific World Journal
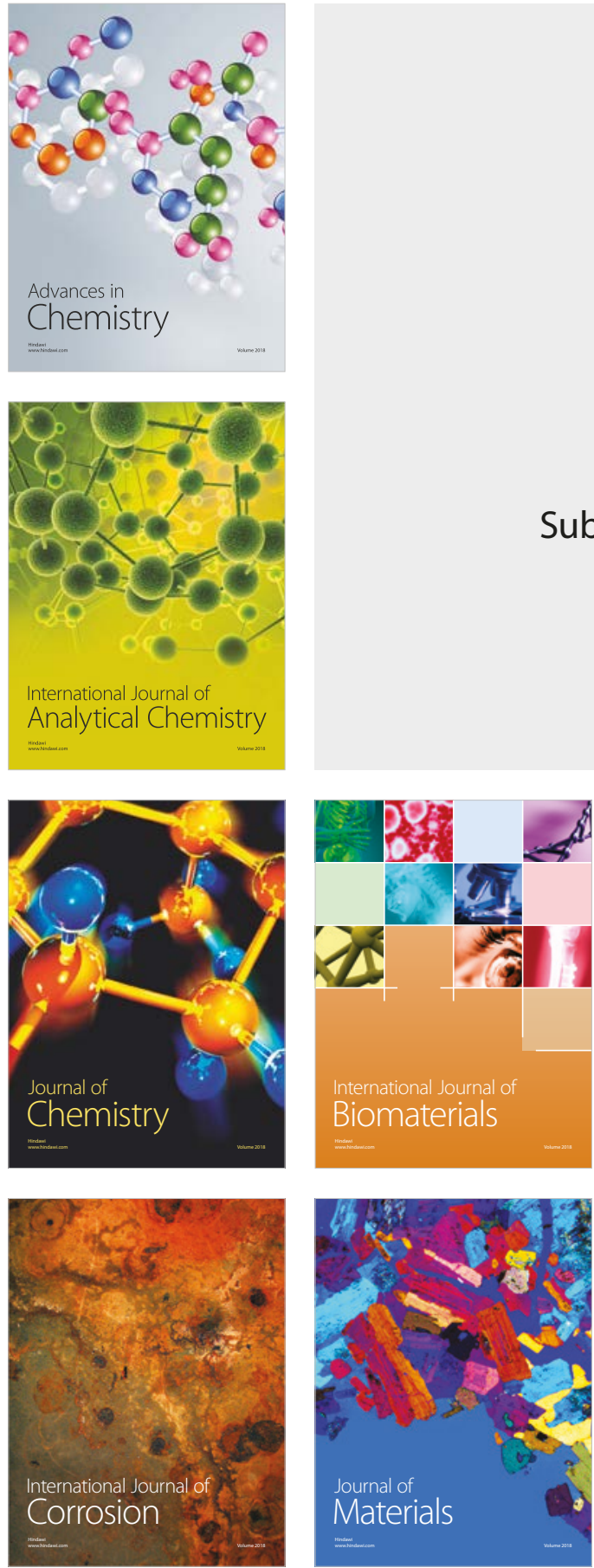

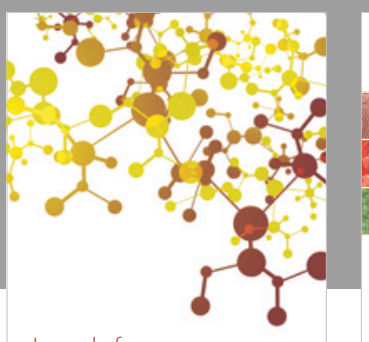

Journal of

Applied Chemistry
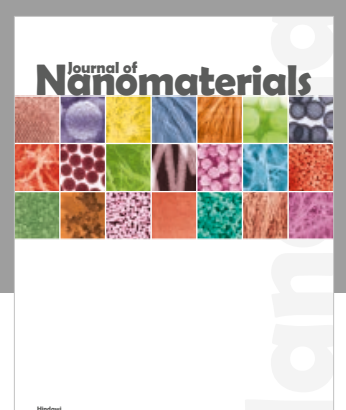

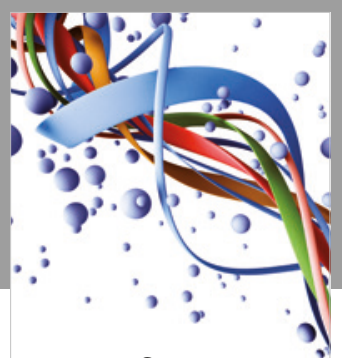

Scientifica

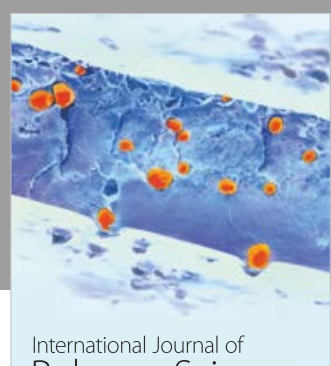

Polymer Science

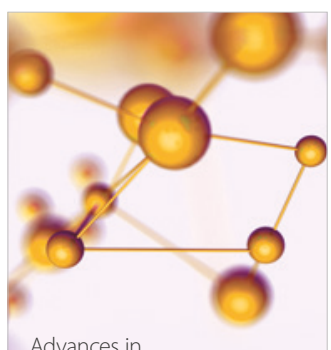

Physical Chemistry
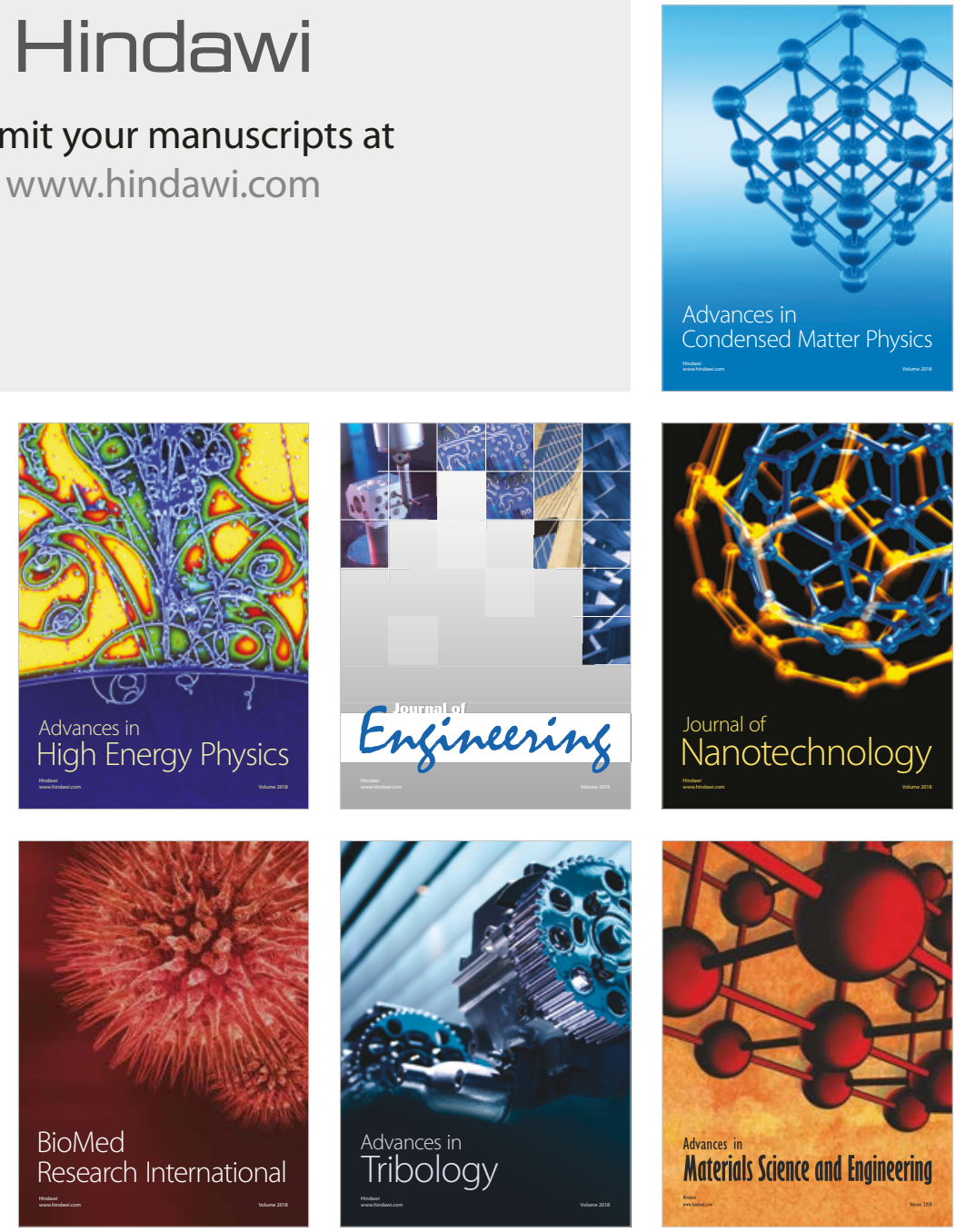